\title{
Urachus Fistula: A Rare First Presentation of Diverticulitis
}

\author{
C. Dickhoffa ${ }^{a}$ M.M. Campo ${ }^{a}$ P.J.A. Ophof ${ }^{b} \quad$ A.F.C. Makkus \\ K.G. Tan ${ }^{\mathrm{a}}$ P.W. Plaisier ${ }^{\mathrm{a}}$
}

Departments of a Surgery, ${ }^{\mathrm{b}}$ Radiology and 'Pathology, Albert Schweitzer Hospital, Dordrecht, The Netherlands

\section{Key Words}

Urachus · Umbilical · Fistula · Diverticulitis

\begin{abstract}
Urachus fistulas are rare, especially in adulthood. In grown-ups urachus fistulas are usually a reflection of Crohn's disease. We present a patient in whom an urachus fistula was the first presentation of diverticulitis of the sigmoid colon. The need for proper preoperative diagnostic imaging is discussed.
\end{abstract}

\section{Introduction}

Urachus fistulas are rare and mostly present in childhood. There are several reports of urachal fistulas in adults but they usually reflect Crohn's disease. We describe a patient whose first presentation of diverticulitis was an urachus fistula.

\section{Case Report}

A 56-year-old obese Caucasian male without significant medical history presented at the outpatient clinic with ongoing purulent umbilical discharge not accompanied by abdominal pain. Physical examination revealed a granuloma at his umbilicus without tenderness of the abdomen. Because initial treatment by application of $\mathrm{AgNO}_{2}$ was not successful, excision of the lesion in day-care surgery was planned. At operation, after excising the granolumatous tissue, a small opening of a canal-like structure was exposed in which a probe could be introduced for about $20 \mathrm{~cm}$ in the direction of the bladder without any resistance. The surgical procedure was then stopped for additional diagnostic imaging of this fistula.

A fistulogram was performed (ig. 1) and with this result, surgery was planned in the clinical setting. At exploration, the proximal part of the tract was situated in the subfascia and proceeded distally into the peritoneal cavity. After opening the abdominal cavity the tract followed the path of the anatomical urachal tract from the umbilicus along the adominal wall to the roof of the urinary bladder. Here the tract ended in a lesion, which appeared to be a process of the sigmoid colon. The tract was excised completely, together with the superficial part of the urinary bladder. Hereafter, the sigmoid colon was mobilised and resected. A primary anastomosis with a deviating double loop ileostomy was performed. 
Histology revealed diverticulitis of the sigmoid colon with abscesses. The specimen also showed scattered urothelial lining without accompanying detrusor muscle (ig. 2 ). The urothelial lining was located at the proximal end of the fistula specimen, not adjacent to the urinary bladder. No connection could be found between the fistula and the resected bladder wall. Thus this urothelial lining was either a remnant of the obliterated urachus or a remnant of an inflamed urachus fistula.

Based on the anatomical location of the fistula canal and the histological properties of the specimen, we conclude that an abscess caused by diverticulitis created a fistula by following the urachus. Three months after laparotomy a colonography with water-soluble contrast was performed. No residual fistula was visible, and the patient was scheduled for surgery to close the ileostomy. This surgery was uneventful.

\section{Discussion}

The urachus is the remnant of the connection between the urinary bladder and the allantois. Normally it obliterates during fetal life (around 32 weeks gestation). After birth it is called median umbilical ligament and may be found as a fibrous cord between the transversalis fascia and the peritoneum. In rare cases, the urachus does not obliterate completely (congenital) or reopens under pathologic conditions (acquired). When the latter become clinically relevant, it is mostly during early adolescence [1]. When pathology of the urachus in adulthood occurs, it usually presents either as an acute abdomen or umbilical infection or fistula and can be due to an infected or ruptured urachal cyst, urachal sinus or underlying inflammatory disease or infection [2-4].

Several case reports describe umbilical fistulas originating from the digestive tract. These abnormalities may present as umbilical fecal discharge and mostly represent underlying inflammatory disease of the colon [5-7]. One report describes a uracho-enteric fistula without pathology of the digestive tract [8]. In our case, we found a fistula of the umbilicus without known pathology of the gastrointestinal tract. Due to the absence of abdominal complaints, no further diagnostics were performed. Only after surgical resection and histological examination by a pathologist the patient appeared to suffer from diverticulitis from the sigmoid.

Once an umbilical-enteric fistula is diagnosed, the treatment of choice is radical surgical resection. The risk of malignant degeneration of the transitional epithelium of the inner urachal duct is unknown but probably small. The risk of recurrent symptoms is probably higher. Therefore, every symptomatic urachal abnormality needs radical resection $[1,9]$. Excision of the entire urachus with a part of the bladder is recommended. When there is underlying pathology, e.g. Crohn's disease or diverticulitis, the resected specimen also needs to contain the pathological part of the gastrointestinal tract. Laparoscopic treatment has been described to give better cosmetic results, although there is a risk of incomplete excision of the urachal remnant [10].

Umbilical abnormalities need to be approached carefully. When there is the slightest possibility of underlying pathology such as urachal cysts or fistulas, omphaloenteric fistulas, gastrointestinal infection or inflammatory diseases, diagnostic modalities like fistulogram, urogram or CT scan must be performed in order to make a solid preoperative plan. 


\begin{tabular}{|c|c|c|c|}
\hline 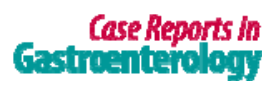 & $\begin{array}{l}\text { Case Rep Gastroenterol 2008;2:287-290 } \\
\text { DOI: } 10.1159 / 000151580\end{array}$ & | Published online: September 20, 2008 & \begin{tabular}{|l} 
@ 2008 S. Karger AG, Basel \\
ISSN 1662-0631 \\
www.karger.com/crg
\end{tabular} \\
\hline
\end{tabular}

Fig. 1. Preoperative fistulogram showing a cutaneous-enteral tract with contrast migration into the proximal and distal direction of the sigmoid colon.

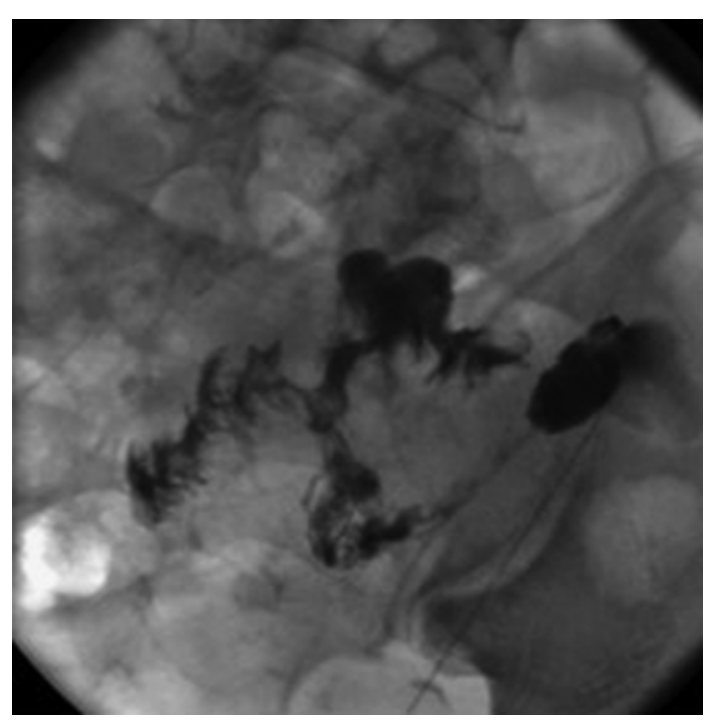

Fig. 2. Diverticulitis adjacent to structure with urothelial lining, not being ureter or bladder wall. Possible urachus remnant.

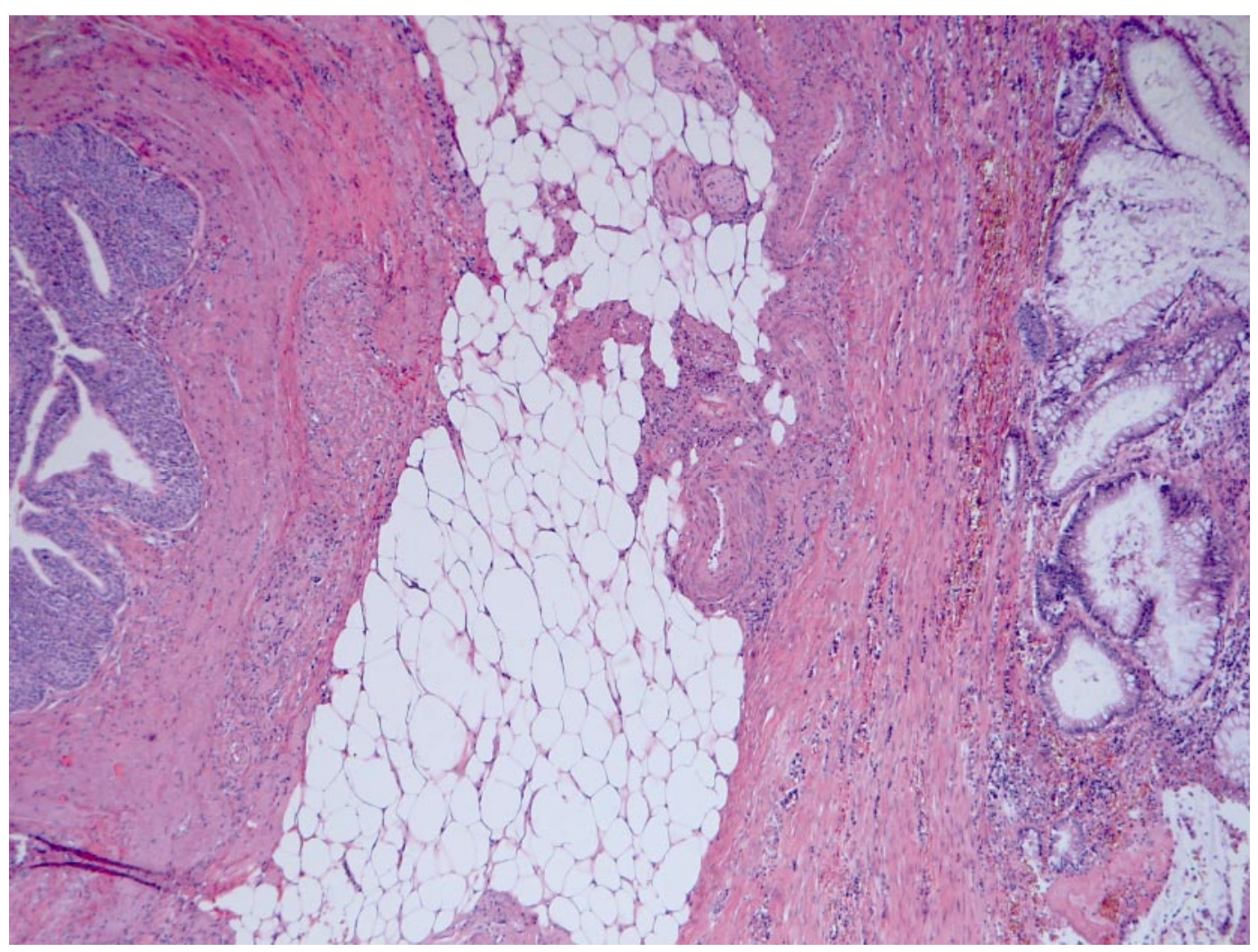




\section{References}

1 Berman SM, Tolia BM, Laor E, Reid RE, Schweizerhof SP, Freed SZ: Urachal remnants in adults. Urology 1988;31:17-21.

2 Keir JA, McGregor R, Richards CJ, Windle R: An unusual presentation of Crohn's disease. Ann R Coll Surg Engl 2004;86:W22-W23.

-3 Quek ML, Shpall AI, Daneshmand S: Colourachal fistula in an adult presenting with feculent umbilical drainage. J Urol 2003;170:184.

4 Hurreiz H, Hussain I, Hamo I: Urachal fistula presenting as umbilical sepsis: a rare case in an adult male. Med Sci Monit 2006;12:CS44-CS47.

5 Bergman R, Sloots CEJ: Diagostic image (246). A man with faecal production of the umbilicus. Ned Tijdschr Geneeskd 2005;149:1940.

6 Klineberg EO, James SP, Dunkin BJ: Crohn's disease complicated by a urachoenteric fistula. Dig Dis Sci 2002;47:1728-1731.

7 Artigas JM, Blasco A, Mota J, Macho J, Gracia AI: Spontaneous enterourachocutaneous fistula in Crohn's disease: sonographic diagnosis. J Clin Ultrasound 1998;26:43-45.

8 Flanagan DA, Mellinger JD: Urachal-sigmoid fistula in an adult male. Am Surg 1998;64:762-763.

9 Blichert-Toft M, Nielsen OV: Diseases of the urachus simulating intra-abdominal disorders. Am J Surg 1971;122:123-128.

10 Cutting CWM, Hindley RG, Poulsen J: Laparoscopic management of complicated urachal remnants. BJU Int 2005;96:1417-1421. 